\title{
Teatralidades no Corpo: o espaço cênico somos nós
}

\section{Resumo}

Este texto aproxima a psicologia fenomenológica ao teatro contemporâneo, discutindo as noções de espacialidade e corporalidade a partir do pensamento do filósofo Maurice Merleau-Ponty. Com base no princípio fenomenológico de que somos "seres em situação", a autora propõe que nosso corpo pode ser, ele mesmo, cenário de uma teatralidade intensamente experienciada por meio de estados, lugares e atmosferas, algo que pode nos fazer prescindir de cenografias estruturadas e dadas de antemão.

Palavras-chave: teatralidade; espacialidade; corporalidade.

\section{Abstract}

This article brings together phenomenological psychology and contemporary theater through the philosopher Maurice Merleau-Ponty's concepts of spatiality and corporality. Starting from the phenomenological principle that we are "beings in situation", the author suggests that our bodies can be, in themselves, the stage of a theatricality that is intensely experienced thanks to states, places, and ambiences, thereby freeing ourselves from the need of pre-established, structured scripts.

Key-words: theatricality; spatiality; corporality.

\section{Introdução}

Esta reflexão é fruto de minha pesquisa das relações entre infância e cena contemporânea, iniciada na pesquisa de Mestrado e continuada no Pós-doutoramento, dois momentos de pesquisa acadêmica sob supervisão da Profa. Dra. Maria Lucia de Souza Barros Pupo (ECA/USP) e com subsídios da bolsa FAPESP. Estivemos ocupados, por cerca de dez anos, com as interações entre a primeira infância e a gênese constitutiva de um "eu", percebendo a possibilidade de um retorno a este estado por meio das artes cênicas, em especial do teatro agora nomeado "não espetacular".

No Mestrado², minha preocupação era a de procurar desconstruir todo e qualquer estereótipo acerca da infância no teatro, especialmente no corpo do ator que

\footnotetext{
${ }^{1}$ Marina Marcondes Machado é docente da Escola Superior de Artes Célia Helena, formadora de professores de teatro e escritora. É psicoterapeuta com mestrado em Artes (ECA/USP), doutora em Psicologia da Educação (PUC/SP) com pós-doutorado em Pedagogia do Teatro (ECA/USP). Sua pesquisa gira em torno das relações entre infância e cena contemporânea.

${ }^{2}$ Pesquisa publicada na forma de livro sob o título Cacos de infância / teatro da solidão compartilhada (São Paulo:
} 
"representasse" a personagem criança. Anos depois, ergui outro campo dramatúrgico, a partir de observação dos modos de ser e estar das crianças em situações de espera, na cidade de São Paulo (2009). Parte da pesquisa "Territórios do brincar", meu pós-doutorado reuniu etnografia e criação dramatúrgica, sempre na direção dos modos de vida da criança, tomando distância de idealizações ou construtos dados de antemão. Entre Mestrado e Pós-doutorado em Artes realizei o Doutorado ${ }^{3}$ no campo da Psicologia da Educação (PUC/SP), debruçando-me sobre a obra de Maurice Merleau-Ponty (1990a; 1990b) que tematiza fenomenologia e infância.

Com base em meus estudos acerca dos existenciais, a saber, a corporalidade, a outridade, a linguisticidade, a espacialidade, a temporalidade e a mundaneidade da criança, desdobrarei neste artigo a gênese de construção das relações eu-espaço, buscando paralelos com a arte não representacional: elo mais caro entre a maneira de ser da primeira infância e o teatro contemporâneo.

Que me perdoem os leitores a forma de bricolagem, mas penso ser necessária uma pitada de nonsense e outra pitada de elementos poético-caóticos para fazer ver a riqueza da fenomenologia da criança.

\section{Chorar e rir no imaginário}

O homem normal e o ator não tomam por reais as situações imaginárias, mas, inversamente, destacam seu corpo real de sua situação vital para fazêlo respirar, falar e, se necessário, chorar no imaginário.

Maurice Merleau-Ponty

Uma das noções mais interessantes para pensar o "si mesmo" do ponto de vista fenomenológico, com foco especial na filosofia merleau-pontiana, é a corporalidade compreendida como "espaço corpo-próprio" (Merleau-Ponty, 1999). Pensar quem somos a partir das relações espaciais é instigante - e pode nos transpor, facilmente, para o campo do teatro: hipótese inicial que desembocou nesta reflexão. Trata-se de experienciar nosso corpo não a partir da espacialidade de posição (sem partir de um "onde"), mas antes de conceber nossa corporalidade como "uma espacialidade de situação" (Merleau-Ponty, 1999, p.146). Partiremos então de um "quem" e seu contorno/ entorno desenhado em gesto e palavra:

O espaço corporal pode distinguir-se do espaço exterior e envolver suas partes em lugar de desdobrá-las, porque ele é a obscuridade da sala necessária à

Annablume / FAPESP, 2004).

${ }^{3}$ Também meu doutorado transformou-se em livro: Merleau-Ponty \& a Educação (Belo Horizonte: Autêntica, 2010). 
clareza do espetáculo, o fundo de sono ou a reserva de potência vaga sobre os quais se destacam o gesto e sua meta, a zona de não-ser diante da qual podem aparecer seres precisos, figuras e pontos. (Merleau-Ponty, idem, ibidem)

A expressão "zona de não-ser", localizada no "fundo de sono", nos remete àquilo que Merleau-Ponty nomeia o "onirismo" da vida infantil: um lugar entre fantasia e realidade, vivido cotidiana e ordinariamente na infância, uma experiência "híbrida", própria das crianças pequenas.

Como acontece, em cada um de nós, a distinção daquilo nomeado "espaço exterior"? Se a fenomenologia nos convida à noção de ser-no-mundo, como trabalhar em nós uma gênese do "eu" como "espaço corpo-próprio", sem dicotomias nem apego ao espaço do geômetra ou do alfaiate que nos tira medidas? O que é um "contorno"?

Merleau-Ponty nos ensina que "não há contorno sem um sujeito que estruture elementos dados para fazer deles figuras" (1990a, p.209). No entanto, haveria um momento pré-reflexivo, anterior ao surgimento

(...) de um limite entre o "fora" e o "dentro", distinção que só existe para um sujeito, ele próprio situado no espaço, que vê de um certo ponto de vista (seu corpo) em relação ao qual a distinção de fora e de dentro toma um sentido. (idem, ibidem)

Nosso contorno é, portanto, construído e vivenciado lentamente, na relação adulto-criança, nos cuidados cotidianos, como alimentação, banho, toque, trocas de fraldas e de roupas. Experienciamos nosso espaço corpo-próprio por meio da proximidade e do distanciamento dos adultos cuidadores, especialmente. Sintonizamos com o psiquiatra existencial Guimarães Lopes:

\footnotetext{
Dentro da extensão entre mim e o outro podem sobrevir dois momentos significativos: o próximo e o distante. O próximo situa-se entre o eu e o tu, o distante entre o eu e o ele. O que é "distante" reflete-se no uso do "se" - como nas frases "ama-se", "procura-se", muito diferente de "amo-te", "procuro-te", em que o "te" reflete diretamente o tu. (grifos do autor) (Guimarães Lopes, 1993, p. 85)
}

Próximos ou distantes, estamos sempre implicados: encontramo-nos em relação; em termos espaciais, estamos em relação... a nós mesmos, ao outro, às coisas do mundo.

Procurando compreender os advérbios de lugar e a maneira de ser própria de quem fala o português do Brasil, de modo a ampliar a reflexão sobre a espacialidade humana, encontrei um interessante texto do linguista Márcio Eduardo Viaro (2003), que nos diz que é próprio da nossa língua a "metaforização do locativo". A cultura católica, por exemplo, pode ser responsável pelas imagens do que temos "por cima" e "por baixo"; mas "o aparecimento da mesma oposição numa cultura não-cristã poderia 
apontar para uma associação natural entre o que é bom e aquilo que está no céu límpido, voando ou entre o que é mau e aquilo que está no chão sujo, rastejando (...)" (2003, p.2). Viaro conversa com uma espécie de "gramática espacial", na qual "associam-se valores às direções"; comenta o que é próprio de traços culturais - algo "que não se associa necessariamente a uma única língua, mas vale como uma herança da visão de mundo" (idem, ibidem).

Se o leitor quiser ficar "por dentro"... que nos acompanhe, por favor!

\title{
O espaço povoado pelo outro
}

\author{
Apaixonite aguda \\ Itamar Assumpção \\ Quando estou longe \\ Quero ficar perto \\ Quando estou perto \\ Quero ficar dentro \\ Quando estou dentro \\ Quero ficar mudo \\ Quando estou mudo \\ Quero dizer tudo
}

A noção fenomenológica de espacialidade, traduzida como relação eu-espaço em termos estritamente humanos, nos remete a espaços ocupados, povoados por outros, o que inclui todos os "não-eu" que ali já se encontravam antes de mim: inicialmente, aqueles que me conceberam; em seguida, aquele que me cuida; depois, aquele a quem procuramos: para estar perto, para brincar junto, para ir e voltar conosco... O espaço esvaziado de sentido, ausente do não-eu, nos anos iniciais, é habitualmente experienciado de modo doloroso, psiquicamente prejudicado, possuidor de silêncio cortante; pois ali, ninguém me espera.

Experienciar o espaço povoado é, portanto, habitar um lugar mais ou menos ruidoso onde alguém me espera, me aguarda: alguém espera que eu acorde - e guarda meu sono; e se uma porta bate inesperadamente pelo vento, e eu acordo um tanto assustado, alguém comunica, carinhosamente: "Foi o vento!".

Os espaços entre-corpos são preenchidos por gesto e palavra - e por muitos tipos de silêncio. Enxerga-se isso em um exercício teatral muito recorrente em oficinas e workshops: propõe-se aos atores andar pelo espaço, procurando, com seu movimento e com sua presença, preencher espaços "vazios" entre eles. Vazio entre aspas, pois em uma sala onde está acontecendo esse tipo de exercício não há de fato um vazio - ou antes, haveria um vazio "grávido" de possibilidades, parafraseando a psica- 
nalista Marion Milner (1991). A criadora dos assim chamados "Jogos Teatrais", Viola Spolin, pede ao ator que dê "substância ao espaço". Em sua técnica para o ator, as caminhadas e os exercícios que auxiliam a "perceber o corpo todo" o levam a uma fenomenologia do espaço, vivido cenicamente. São exemplos de seus comandos para o ator:

Sinta a forma de seu corpo quando se move pelo espaço! Agora deixe que o espaço sinta você! O seu rosto! Os seus braços! O seu corpo todo! Mantenha os olhos abertos! Espere! Não force! Você atravessa o espaço e deixa que o espaço o atravesse! (Spolin, 1999, p.135)

Também Kazuo Ohno, dançarino criador do butoh, noutra chave de direção cênica, afirmou a inexistência do vazio para o ator, dançarino ou performer:

De maneira nenhuma pode-se dizer que não haja nada num palco vazio, num palco que se pise de improviso. Pelo contrário, existe ali uma infinidade de coisas e acontecimentos, sem que se saiba como e quando. (Ohno, 1997)

Mas condições de adoecimento psíquico podem revelar um corpo encarnado de vazio e solidão, sofrimento e silêncio, nos remetendo a outros lugares, muitos dos quais extremamente assombrosos; surgem assim habitantes dos palcos psiquicamente vazios:

\begin{abstract}
Dentro do horizonte da espacialidade observamos por vezes um caminhar em viés, esquinado, por outras vezes em círculo. Ou seja, no primeiro caso, quase nunca encontrando o outro a não ser por casualidade, no segundo caso fazendo uma aproximação mas logo se distanciando para repetir o mesmo movimento. Noutras situações verificamos a primazia da vivência do vazio nada havendo, do ponto de vista humano, que o preencha ou, então, a corporalidade procurando abertura no outro para extravasar a espacialidade cerrada. Ainda outras vezes verificamos hiperordenação: o relacionamento segue pré-determinações quase rígidas, fixas, meticulosas, postas umas a seguir às outras, ou, então, a espacialidade é vertiginoso buraco negro onde tudo se consome nada restando afinal das possibilidades de relação. Pode também a espacialidade aparecer à superfície atrativa, chamativa, cheia de engodos descontínuos, dando lugar ao saltitar sem um verdadeiro salto para a passagem a um outro modo de ser. (Guimarães Lopes, 1993, p.85).
\end{abstract}

\title{
Lugares de mundaneidade e faz de conta
}

Sou o espaço onde estou Noel Arnaud

Outro dia, dentro de um ônibus em São Paulo, presenciei um acontecimento interessante entre uma mãe e seu bebê: uma cena. A nenê devia ter entre 7 e 9 meses. A mãe queria "ensinar" sua filha a dizer: "Mamãe." Repetia, por diversas vezes: "Mamãe"; "mã mã mã"; "Mamãe". Certamente a mãe não percebia a situação como eu a percebia: ela dizia "Mamãe, mã mã mã" e sua filhinha respondia com seu corpo, dando tapinhas 
suaves nela, apontando quem é a mamãe. Vi no gesto da criança beleza e amorosidade únicas. A espacialidade viva e preenchida entre elas, o dizer da mãe e a resposta não-verbal da filha, os corpos dizendo que se complementavam e se compreendiam... com certeza é a isso que os psicanalistas nomeiam uma experiência de "amor incondicional"! Se aquele bebê pudesse se perguntar "Qual o meu lugar no mundo?", a resposta certa seria: "O colo da minha mãe".

Haveria uma sequência espacial comum a quase todos nós, humanos e mamíferos... sequência espacial-existencial: habitar a barriga da mamãe; sair da barriga da mamãe; andar de colo; repousar no berço; arrastar-se, engatinhar, para depois andar. Assim, o espaço-corpo-próprio mostra-se como um lugar a ser habitado em relação: relaciona-se, comunica-se com outros contornos, limites e espaços, os outros e as coisas do mundo.

A espacialidade vivida, a espacialidade existencial ("estar por dentro!", "estar por fora"...) dialoga todo o tempo com a espacialidade de posição:

\section{Estou escondido \\ Debaixo da mesa; \\ Ninguém sabe, porém, \\ Onde estou. Que beleza!}

Este é o início de um ingênuo poema que lia e relia na minha infância. Tratava-se de um bebê escondido dos pais...: "já ouvi o papai perguntar / (...) / -- Onde está o nenê? / Já olhou na cozinha?" (Aldis apud Machado, 1998). Esconde-esconde! Uma prática ancestral de brincadeira de espacialidade - aparecer e sumir, desaparecer e ser encontrado - muito interessante para pensarmos as possíveis descobertas de "qual o meu lugar no mundo?".

Esconder-se para ser achado: convite ao deslocamento do outro até mim, quando o espaço ganha outra dimensão; quero e não quero ser achado, e a visita do outro ao meu espaço-esconderijo é o fim do jogo... mas pode significar também um alívio: continuar existindo! Poder sair correndo! Gritar! Libertar-se da imobilidade anterior, necessária para não ser achado.

Para D. W. Winnicott (1994), a mãe que esconde seu bebê por detrás de um pano ou fralda e depois o redescobre ("Achou!") revive uma das primeiras formas culturais humanas, algo relacionado a saber "brincar de ilusão": ilusão de estar escondido, mas "achado" bem inteirinho ali, diante da mãe; e a resposta adulta, na forma de jogo, é também ilusória: "acreditar" que seu nenê havia sumido... Este mote "simples assim" está, para Winnicott, na origem de todas as atividades cria- 
tivas/criadoras - teatro, cinema, poesia, filosofia, ciência e religiosidade: a ponto do psicanalista inglês nomear seu conceito de espaço potencial também como "espaço de ilusão" e "área do consolo".

De que me consolo? Do fato de minha mãe não ser "eu"; do fato de que sou totalmente dependente dos cuidados, dizeres e ações dos adultos ao meu redor; da fagulha, acesa ao nascer, de que "tudo que nasce, morre". Tudo isso é ingrediente do brincar de faz de conta - ou, como propõe Sarmento (2004), da "fantasia do real" própria da primeira infância.

De que me iludo? Me iludo de ser o criador do mundo.

\section{Situações e imagens de teatralidades}

Há uma espécie de construção sintática em português e outras línguas românicas que não tem tido a atenção que merece. Trata-se de sintagmas em que um verbo é seguido de um advérbio de lugar ou de uma locução adverbial equivalente. Tal combinação forma uma imagem básica, donde se derivam outros significados menos evidentes. (Márcio Eduardo Viaro)

Ampliar o horizonte da espacialidade, da relação eu-espaço, nos faz visitar, adultos que somos, a linguisticidade e o campo gramatical de nossa língua-mãe. Proponho concretizarmos essa boa ampliação de vocabulário: não algo feito por meio do dicionário, mas antes, no seu espaço corpo-próprio e megulhado nas relações. Será rico perceber a gramática das ações espaciais, visitando os advérbios de lugar em seu corpo vivido. Jean-Pierre Ryngaert (1992), ao discutir as marcas espaciais de textos teatrais, diz, sobre a noção de "espaço metafórico": "O lugar da palavra é talvez o verdadeiro espaço do confronto já que visitar o outro é, na peça, conversar” (1992, p.101).

Wim Wenders escreveu um poema que homenageia Pina Bausch e que pode ser uma estrela guia em como as palavras nos convidam a "algures" - outros espaços, que podem "nascer progressivamente da linguagem" (Ryngaert, 1992):

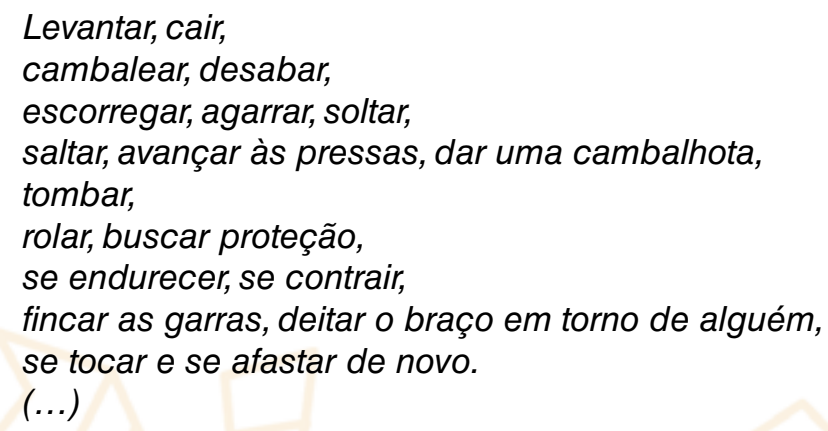

Wenders conduz sua homenagem a Pina Bausch a uma espécie de jogo de palavras: 


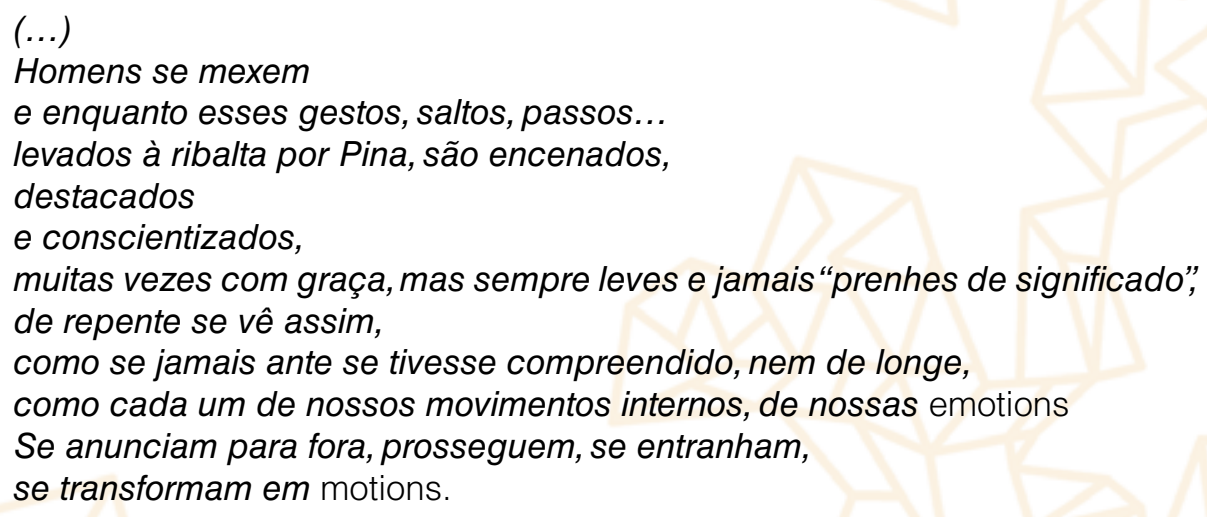

O texto poético de Wim Wenders também é convite para pensar teatralmente: seus dizeres nos levam para longe do psicologismo - ou, noutro modo de dizer, para longe de um tipo de representação emotiva - e nos propõe entranhas transformadas em movimento e ação. O cineasta procura palavras e cria um texto que revela a enorme contribuição de Pina Bausch à cena contemporânea - a encenação que não representa: é, encarna no corpo um leque de emoções, não mais “interpretadas", mas agora mostradas, escancaradas ao espectador, de modo que ele mesmo se entranhe naquilo que a dança assistida the propõe.

Desse modo, o espectador levará embora o cenário em seu espaço corpo-próprio, "motions", forma de memória e possibilidade de digressão daquilo que se assistiu no teatro. Pontuo ao leitor que as crianças fazem isso o tempo todo, em suas ações cotidianas mais ordinárias: impregnam-se, corporificam prazer e medo, advindos da experiência de viver o mundo. Reside especialmente neste paralelo entre ser criança e ser performer minha contribuição como pesquisadora de teatro4.

\section{Estados, atmosferas e temporalidade: nosso corpo próprio é lugar de teatralidades}

A linguagem estabelece uma relação com o espaço, a ação dá-lhe um sentido

Jean-Pierre Ryngaert

Considerar que o espaço não está cheio de significações dadas de antemão, como relembrou Wim Wenders, ou ainda, procurar significações nos espaços, nos lugares, transformando-os em "cenários" simples, cotidianos, como paisagens de nossa relação com o outro e mergulhados no mundo, seria próprio de todos aqueles que viveram o que Winnicott (1994) nomeia "um bom começo" “Um bom começo" é um início de vida com boa maternagem, ou seja, indício da vitalidade de bebês que são

\footnotetext{
${ }^{4}$ Para saber mais, ver MACHADO, Marina Marcondes. "A criança é performer". Revista Educação \& Realidade. V.35, n.2. p.115-137. Porto Alegre: UFRGS, 2010.
} 
cuidados por adultos responsáveis e responsivos: adultos que cuidam para que a realidade nos seja apresentada em pequenas doses; adultos que, concomitantemente, nos preservam e nos levam a novos lugares para vivenciar novas situações.

A noção de "mãe suficientemente boa", proposta por Winnicott, revela um adulto que carrega uma certa sabedoria zen: ausente e presente ao mesmo tempo; significa estar sempre por ali, mas sem interferir na maneira de ser e estar da criança, direta ou invasivamente. No vazio-cheio entre um adulto presente e ausente e uma criança pequena está aquilo que Winnicott nomeou "espaço potencial." Algo que ele mesmo disse ser "um lugar conceitual," modo de dizer algo sobre o afeto entre a mãe e o bebê, quando as coisas estão indo bem.

O espaço potencial não é um lugar no sentido da espacialidade de posição, mas é um lugar psíquico compartilhado, habitado pelo bebê com sua mãe. É o lugar da brincadeira (playground); é o lugar da ilusão de que somos, sim, os criadores do mundo! Fechar os olhos fazendo o mundo desaparecer é uma ação infantil que não deve ser questionada ou replicada pelo adulto realista. É fundamental ser cúmplice da capacidade criativa da criança pequena, cumplicidade que deixará rastro e lastro: rumo à experiência estética, filosófica e religiosa; rumo à invenção na arte, ciência e poesia. Assim, a noção de "espaço potencial" não quer revelar apenas uma geografia, é também história e mundaneidade, é lugar de existir:

Espacialidade e corporalidade estão tão intimamente ligadas que por vezes se confundem. Heidegger falava duma topologia do ser. Em psico(pato)logia é importante a consideração simbólica do "topus" no acontecer corporal. (Guimarães Lopes, 1993, p. 85)

Proponho, para finalizar, que o cenário central para os acontecimentos performativos cotidianos é o performer ele mesmo, ou seja, o espaço corpo-próprio. Sua corporalidade em relação: fora, dentro, entre; profunda ou superficialmente implicado. Nesta chave, experienciar teatralidades prescinde de cenários no sentido tradicional do termo. E, no sentido da sociologia que trabalha com as noções de papéis sociais, quanto mais autêntica a experiência daquele que performa, menos máscaras sociais, figurinos rebuscados, dramaturgia pronta e requisitos cenográficos prévios seriam necessários para a comunicação transformadora entre-humanos: aquela que nos supreende por não ser previsível, algo capaz de nos "tirar o chão" - bem como nos colocar "para cima" na hora da queda. 


\section{Referências}

BACHELARD, Gaston. A Poética do Espaço. São Paulo: Martins Fontes, 1993.

LOPES, Raul Guimarães. Clínica Psicopedagógica / Perspectiva da antropologia fenomenológica e existencial. Hospital do Conde Ferreira: Porto, 1993.

MACHADO, Marina Marcondes. A Poética do Brincar. São Paulo: Edições Loyola, 1998.

MERLEAU-PONTY, Maurice. Fenomenologia da Percepção. São Paulo: Martins Fontes, 1999.

MERLEAU-PONTY, Maurice. Merleau-Ponty na Sorbonne/Resumo de cursos: Filosofia e Linguagem. Campinas: Papirus, 1990a.

MERLEAU-PONTY, Maurice. Merleau-Pontyna Sorbonne/Resumo de cursos: Psicossociologia e Filosofia. Campinas: Papirus, 1990b.

MILNER, Marion. A loucura suprimida do homem são. Rio de Janeiro: Imago, 1991.

OHNO, Kazuo. Catálogo da "Temporada SESC Outono 97". SESC SP, Maio, 1997.

ORLANDI, Eni. As formas do silêncio. Campinas: Editora UNICAMP, 2007.

RYNGAERT, Jean-Pierre. Introdução à análise do teatro. Porto: Edições ASA, 1992.

SARMENTO, Manuel. "As Culturas da Infância nas Encruzilhadas da 2å Modernidade". Disponível em: http://cedic.iec.uminho.pt/Textos_de_Trabalho/textos/encruzilhadas.pdf. Acesso em 26/04/2011

SPOLIN, Viola. O jogo teatral no livro do diretor. São Paulo: Perspectiva, 1999.

VIARO, Márcio Eduardo. "Estruturas cristalizadas de verbo+advérbio de lugar no português". Boletim da Associação Brasileira de Lingüística. Fortaleza: UFC/Imprensa Universitária, 2003. v. 26, p. 464-466.

WENDERS, Wim. "Que tesouro mora dentro de nossos corpos...". Revista Humboldt. Bonn: Goethe Institut, 2010. N. 102, ano 51. p. 30-33.

WINNICOTT, Donald Woods. Playing and Reality. Londres e Nova lorque: Tavistock/Routledge, 1994.

\section{Outros links úteis}

Sites de artistas citados neste artigo

Kazuo Ohno Dance Studio

Pina Bausch

Wim Wenders

Outros

Agachamento - cotidiano, arte e infância, website da autora

Improvisation on theater, de Viola Spolin

Verbete Maurice Merleau-Ponty da Standford Encyclopedia of Philosophy

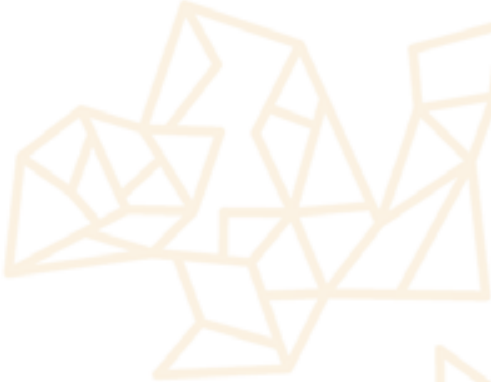

